\title{
Mechanism of action of Drosophila Reaper in mammalian cells: Reaper globally inhibits protein synthesis and induces apoptosis independent of mitochondrial permeability
}

\author{
SWG Tait ${ }^{1}, A B$ Werner ${ }^{1}, E$ de Vries ${ }^{1}$ and J Borst ${ }^{\star, 1}$ \\ ${ }^{1}$ Division of Immunology, The Netherlands Cancer Institute, 1066 CX \\ Amsterdam, The Netherlands \\ * Corresponding author: J Borst, Tel: + 31-20-5122056; E-mail: j.borst@nki.nl
}

Received 29.10.03; revised 08.1.04; accepted 09.1.04; published online 26.3.04 Edited by S Kumar

\begin{abstract}
Drosophila Reaper can bind inhibitor of apoptosis proteins (IAP) and thereby rescue caspases from proteasomal degradation. In insect cells, this is sufficient to induce apoptosis. Reaper can also induce apoptosis in mammalian cells, in which caspases need to be activated, usually via the mitochondrial pathway. Nevertheless, we find that Reaper efficiently induces apoptosis in mammalian cells in the absence of mitochondrial permeabilisation and cytochrome $c$ release. Moreover, this capacity was only marginally affected by deletion of Reaper's amino-terminal IAP-binding motif. Independent of this motif, Reaper could globally suppress protein synthesis. Deletion of 20 amino acids from the carboxy-terminus of Reaper fully abrogated its potential to inhibit protein synthesis and to induce apoptosis in the absence of IAP-binding. Our findings indicate that the newly identified capacity of Reaper to suppress protein translation can operate in mammalian cells and may be key to its proapoptotic activity.

Cell Death and Differentiation (2004) 11, 800-811.

doi:10.1038/sj.cdd.4401410

Published online 26 March 2004
\end{abstract}

Keywords: Reaper; mitochondria; cytochrome $c$; IAP; mammalian cells

Abbreviations: $\mathrm{CHX}$, cycloheximide; Cyt $c$, cytochrome $c$; GFP, green fluorescent protein; IAP, inhibitor of apoptosis protein; IBM, IAP-binding motif; PIP, phosphatidyl inositol phosphate; TBS, Tris-buffered saline

\section{Introduction}

Studies in lower eukaryotes, primarily Caenorhabditis elegans and Drosophila melanogaster, have provided great insight into the basic mechanisms underlying apoptotic cell death. ${ }^{1,2}$ Concomitant work in mammals has shown that the fundamental processes and protein families involved in apoptosis are evolutionarily conserved. Given this conservation, several apoptosis-regulatory proteins are functional in mammalian as well as lower eukaryotic organisms. The Drosophila protein Reaper is one of these: it induces apoptosis in both Drosophila and mammalian cells. ${ }^{3,4}$ Reaper was originally identified in a genetic screen for molecules involved in developmental cell death in the fruit fly. Loss of H99 chromosomal region, which encodes Reaper, Grim and Hid, results in embryonic cell accumulation and imparts resistance to various apoptotic stimuli. ${ }^{5}$ Transcriptional control of Reaper expression appears to be the primary mechanism governing its activity. Reaper may be upregulated in response to developmental cues, for example, by the Hox transcription factor, ${ }^{6}$ or in response to environmental stimuli, notably by the Drosophila p53 orthologue. ${ }^{7}$

It has recently been resolved that Reaper can induce apoptosis in insect cells by antagonising the function of inhibitor of apoptosis proteins (IAPS). IAPs possess characteristic amino-terminal baculovirus IAP repeats (BIR) that interact with caspases. ${ }^{8}$ Many also have a carboxy-terminal RING finger motif, which binds E2 ubiquitin-conjugating enzymes and classifies IAPs as E3-type ubiquitin ligases. ${ }^{9}$ IAPs can inhibit caspase-9 and effector caspases and thereby block apoptosis in response to a variety of stimuli. ${ }^{8}$ IAPS accomplish this inhibition by binding to caspases and catalysing their proteasomal degradation. Drosophila IAP1 (DIAP1) possesses a RING finger and E3 ubiquitin ligase activity. Under normal circumstances, the Drosophila caspase Dronc is ubiquitinated by DIAP1 and its associated E2 (Morgue or UBCD1) and targeted for proteasomal degradation. Following its upregulation, Reaper displaces Dronc from DIAP1. Binding of Reaper to DIAP1 leads to auto-ubiquitination and proteasomal degradation of DIAP1 instead, thus facilitating Dronc stabilisation and activation. ${ }^{10-15}$

Other Drosophila proteins share the ability to neutralise DIAP function. These include Grim and Hid as well as the recently identified DNA damage response protein Sickle, whose gene maps adjacent to the $\mathrm{H} 99$ region. ${ }^{16-18}$ In addition, the Jafrac2 protein, which resides in the endoplasmic reticulum, but is released during apoptosis, shares this property. ${ }^{19}$ Reaper, Grim, Hid and Sickle share a motif in the extreme amino-terminal seven amino acids, which is required for DIAP binding. ${ }^{17}$ This so-called IAP-binding motif (IBM) is also present in the mature form of Jafrac2. ${ }^{19}$ Loss of DIAP1 results in early embryonic death, also in the absence of the $\mathrm{H} 99$ region encoding Reaper, Grim and $\mathrm{Hid},{ }^{14}$ indicating that removal of caspase inhibition is sufficient to trigger apoptosis in Drosophila.

The finding that Reaper, Grim, Hid and Sickle can induce apoptosis in mammalian cells suggests conservation of this death pathway. $4,17,20$ Nevertheless, database searching reveals no obvious homologues of Reaper and its relatives in the human genome. Recently though, Smac/Diablo and the 
serine protease $\mathrm{HtrA} / \mathrm{Omi}$ were defined as functional Reaper homologues in human, in that they possess IAP binding and neutralisation function. ${ }^{21-23}$ Both proteins are released from mitochondria in response to apoptotic stimuli. They are synthesised as precursors with an extensive mitochondrial targeting sequence at their amino terminus. Removal of these sequences in the mature forms exposes an AVPI/AVPS motif in Smac/Diablo and HtrA2/Omi, which resembles the motif found in the Drosophila homologues and allows interaction with the BIR domains of IAPs. ${ }^{24}$

However, the capacity of Reaper and relatives to inhibit IAP function cannot fully explain its potential to kill mammalian cells. In Drosophila, removal of IAP-mediated caspase inhibition is sufficient to cause apoptosis. ${ }^{14,25}$ In mammalian cells, however, removal of IAP-mediated inhibition sensitises cells to apoptosis but does not trigger caspase activation and apoptosis. $^{21,22}$ An additional signal is required for caspase activation. In line with the existence of another pro-apoptotic mechanism, at least in Reaper and Grim, deletion of their IBM did not significantly affect their capacity to induce apoptosis in human breast carcinoma cells. ${ }^{4}$

Recently, a 15-amino-acid internal region was defined in Grim, termed the GH3 domain, which is predicted to fold as an amphipathic $\alpha$-helix. Deletion of the GH3 domain strongly reduces Grim's pro-apoptotic activity both in flies and in mammalian cells. ${ }^{26,27}$ Certain residues within the GH3 domain are conserved in Reaper and Sickle. ${ }^{26}$ In isolation, Grim's IBM and GH3 domains each could trigger apoptosis in insect cells in an independent and cooperative manner. ${ }^{26}$ The mechanism by which the GH3 domain triggers an apoptotic response is not resolved. However, new data suggest that it acts via a novel mitochondrial pathway. During apoptosis induction, the $\mathrm{GH} 3$ domain targets Grim to mitochondria. ${ }^{26,27}$ The GH3 domain was found to be required and sufficient to induce release of cytochrome $c$ (Cyt $c$ ) from mitochondria in mammalian fibroblasts. This took place in the absence of caspase activation and was independent of the presence of $\mathrm{Bax}$ and $\mathrm{Bak}^{27}$ which suggests lack of involvement of $\mathrm{BH} 3$ domain-only proteins in this pathway.

An independent line of investigation has implicated mitochondria in apoptosis induction by Reaper. Reaper was found to promote the spontaneous pro-apoptotic activity of Xenopus oocyte extracts, which is read out on nuclei. This required a mitochondrial fraction and was accompanied by Cyt $c$ release. ${ }^{28}$ The subsequent identification of the Xenopus protein Scythe as a Reaper-binding partner ${ }^{29}$ and additional studies led to a model in which Reaper induces the dissociation of a Cyt $c$-releasing activity from Scythe. ${ }^{30}$ Thus far, however, this activity has not been identified, nor has this pathway been analysed in mammalian cells.

While investigating the impact of Reaper and Grim on IAP protein levels, two groups have noted that these two family members not only direct IAP degradation, but can also globally inhibit protein translation, at least in reticulocyte lysates and Xenopus oocytes. ${ }^{14,15}$ It is presently unknown which structural motifs in Reaper and Grim are responsible for this activity and how it relates to their capacity to induce apoptosis.

In summary, it is not resolved by which mechanism(s) Reaper induces apoptosis in mammalian cells. In this work, we have examined how Reaper can bring about apoptosis in human carcinoma cells in the absence of IAP binding. We have studied its potential to activate the classical mitochondrial pathway and to interfere with translation and related this to its pro-apoptotic capacity.

\section{Results}

\section{Reaper and $\triangle \mathrm{IBM}$ Reaper distribute throughout cytosol and nucleus}

Our aim was to investigate by which mechanism(s) Reaper induces apoptosis in human cells. We used not only full-length Reaper, but also a Reaper mutant lacking the seven-residue amino-terminal motif required for IAP binding. This mutant protein was used to reveal a potential pro-apoptotic pathway that did not rely on Reaper's ability to inhibit IAP function. Reaper or Reaper lacking the IBM ( $\triangle$ IBM Reaper) were fused with green fluorescent protein (GFP) at the carboxy-terminus. These chimeric proteins were expressed by transient transfection in HeLa cervix carcinoma cells. To visualise mitochondria, cells were labelled with red fluorescent MitoTracker. Cells that displayed a healthy appearance at $24 \mathrm{~h}$ posttransfection were analysed by confocal laser-scanning microscopy. Reaper-GFP was found to distribute diffusely throughout the cell (Figure 1, Panel I). Specific co-localisation of Reaper-GFP and mitochondria was not detected. $\triangle$ IBM Reaper-GFP, similar to Reaper-GFP, distributed throughout the cytoplasm and nucleus and did not co-localise with mitochondria (Figure 1, Panel II). Reaper carrying an aminoterminal Myc tag displayed an identical cellular distribution as the Reaper- or $\triangle$ IBM Reaper-GFP fusion proteins (data not shown). These results demonstrate that in nonapoptotic cells, Reaper does not selectively localise to mitochondria or other intracellular organelles, but is cytosolic and nuclear. Secondly, removal of the amino-terminal IBM does not influence Reaper's intracellular localisation. Finally, fusion to GFP does not alter Reaper's subcellular distribution.

\section{Reaper and $\triangle$ IBM Reaper induce caspase- dependent cell death}

Next, the ability of Reaper or $\triangle I B M$ Reaper to induce apoptosis in human cells was examined. HeLa cells were analysed for the incidence of cell death 2 days after transfection. As a positive control for caspase activation and apoptosis, the cells were stimulated with UV light. Prolonged expression of Reaper or $\triangle \mathrm{IBM}$ Reaper resulted in cell detachment and death (Figure 2a). The death had features characteristic of apoptosis, such as membrane blebbing (Figure 2a), chromatin condensation and nuclear fragmentation, as observed in cells treated with UV light. Quantification of apoptosis incidence in transfected cells, based on these morphological features, showed that Reaper and $\triangle \mathrm{IBM}$ Reaper had a similar pro-apoptotic capacity (Figure 2a). Furthermore, apoptosis caused by Reaper and $\triangle \mathrm{IBM}$ Reaper was inhibited by the pan-caspase inhibitor zVAD-fmk, indicating that both proteins caused cell death by activating the apoptotic execution machinery. Cell lysates were prepared from Reaper-GFP or $\triangle$ IBM Reaper-GFP expressing 

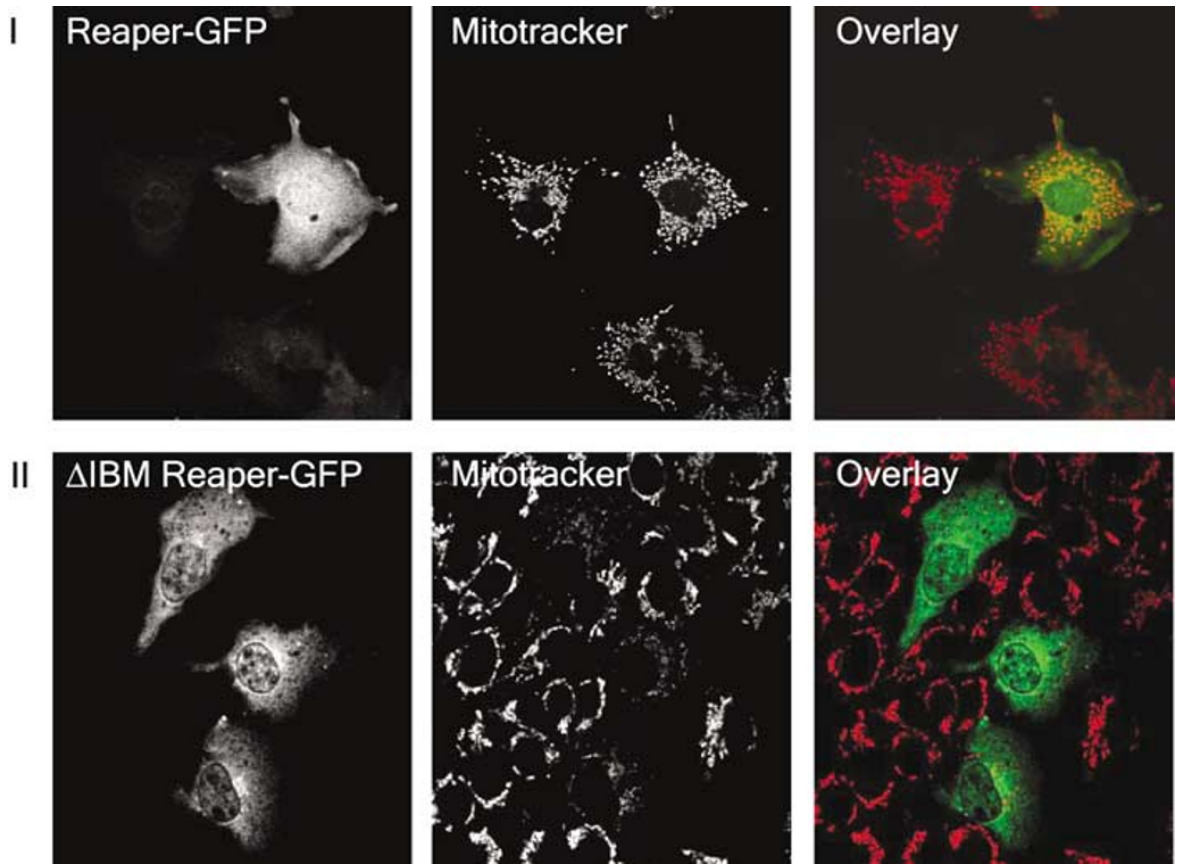

Figure 1 Subcellular localisation of full-length Reaper and a Reaper mutant lacking the IBM $(\Delta \mid \mathrm{IBM})$. Human HeLa cervix carcinoma cells were transfected to express the green fluorescent chimeric proteins Reaper-GFP (Panel I) or $\Delta$ IBM Reaper-GFP (Panel II). Cells were labelled with red fluorescent MitoTracker to stain mitochondria and subsequently fixed. Samples were analysed by confocal laser-scanning microscopy. The distribution of expressed proteins (green) and mitochondria (red) are shown separately and together (overlay)

HeLa cells 2 days after transfection and analysed for caspase processing by immunoblotting (Figure $2 \mathrm{~b}$ ). Reaper and $\triangle \mathrm{IBM}$ Reaper induced proteolytic processing of pro-Caspase-7 to a similar extent, as evidenced by the appearance of the cleaved form of Caspase-7. As a measurement of effector caspase activity, proteolytic cleavage of the effector caspase substrate PARP was examined. Overexpression of Reaper and $\triangle \mathrm{IBM}$ Reaper resulted in a reduction of the amount of full-length PARP protein and a corresponding increase in PARP cleavage fragment (Figure 2b). Caspase-7 and PARP cleavage was not very efficient in the cell population that included Reaper- and $\triangle \mathrm{IBM}$ Reaper-expressing cells, as compared to UV-treated cells. This can be explained by the relatively low transfection efficiency of HeLa cells.

The collective results demonstrate that Reaper brings about caspase-mediated apoptotic death in human cells. Surprisingly, the ability of Reaper to activate the apoptotic execution machinery was virtually unaffected by deletion of the amino-terminal seven amino acids constituting the IBM.

\section{Apoptosis induction by Reaper does not involve mitochondrial permeabilisation}

To investigate whether the apoptotic mechanism employed by Reaper involved a mitochondrial pathway, we first examined whether it could induce Cyt $c$ release from mitochondria in vivo. Reaper-GFP and $\triangle$ IBM Reaper-GFP were expressed in HeLa cells. At 2 days after transfection, cells were analysed for Cyt $c$ content by flow cytometry of digitonin permeabilised cells. As a positive control, we also transfected cells with HA- tagged Bax and GFP-tagged histone and examined Cyt $C$ release. A large percentage of Bax overexpressing cells showed Cyt $c$ release (Figure $3 a$ ), in accordance with its defined mechanism of action. ${ }^{31}$ In contrast, expression of Reaper or $\triangle \mathrm{IBM}$ Reaper did not cause Cyt $c$ release (Figure 3a). As a second means of analysing the effect of Reaper on mitochondrial permeabilisation, we examined Reaper-transfected cells for the localisation of Cyt $c$ by confocal microscopy (Figure 3b). Unstimulated HeLa cells displayed a punctate Cyt $c$ staining (Panel I), which colocalised with MitoTracker (not shown). Stimulation with UV light resulted in dispersion of Cyt $c$ throughout the cell, indicative of its release from the mitochondria (Panel II). Nuclear condensation, as visualised by TO-PRO-3 dye, confirmed the apoptotic phenotype of cells in which Cyt $c$ had been released from the mitochondria (Panel II). Apoptotic Reaper-expressing cells were round and/or blebbing and displayed nuclear condensation (Panel III). In such cells, Cyt $c$ distribution was consistently punctate, as in surrounding, untransfected non-apoptotic cells. $\triangle$ IBM Reaper-expressing cells undergoing apoptosis could also be recognised by a rounded morphology and nuclear condensation (Panel IV). Similarly, in these cells Cyt $c$ did not re-distribute into the cytosol. These results indicate that Reaper, as well as the Reaper mutant devoid of IAP-binding activity, can induce apoptosis in human cells in the absence of detectable mitochondrial Cyt $c$ release. Both Reaper and $\Delta$ IBM Reaper accumulated in perinuclear areas in apoptotic cells (Panels III and IV). Some degree of co-localisation of Reaper/AIBM Reaper and mitochondria (Cyt $c$ ) was observed in such areas (overlays, Panels III and IV). The apparent translocation of 
Reaper (and $\triangle \mathrm{IBM}$ Reaper) to the perinuclear region and the partial co-localisation with mitochondria was independent of caspase activity, since it was also observed in cells cultured in the presence of zVAD-fmk (Panel V).

To determine whether Reaper required mitochondrial permeabilisation and the release of mediators (perhaps other than Cyt $c$ ) to induce apoptosis, the effect of $\mathrm{Bcl}-2$ on Reaper-

a

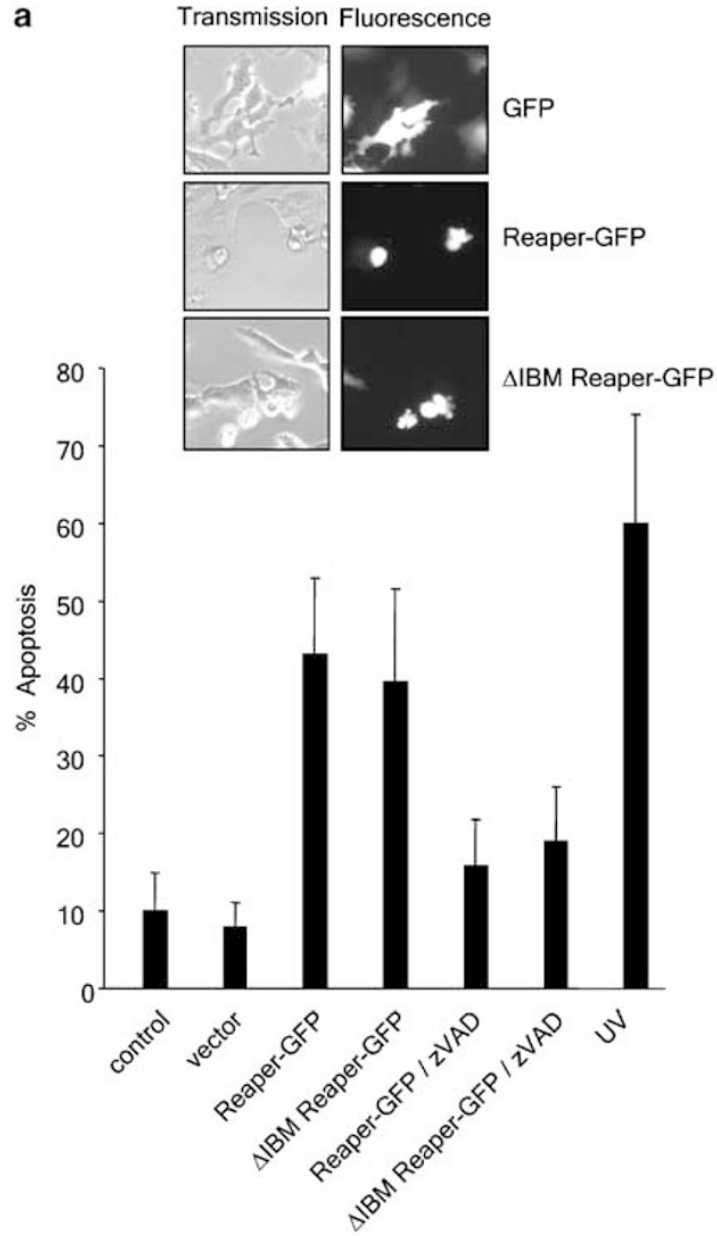

b

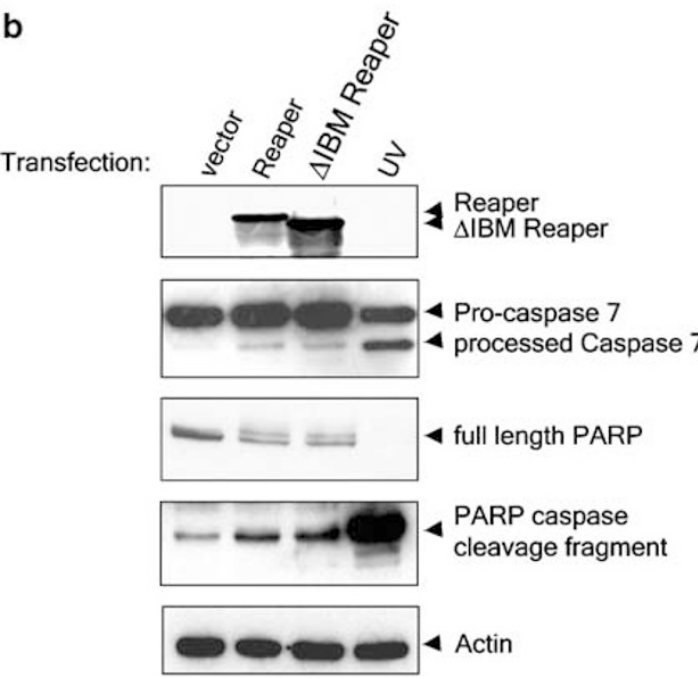

mediated cell death was examined. Bcl-2 overexpression reliably blocks mitochondrial permeabilisation by antagonising the function of $\mathrm{BH} 3$ domain-only $\mathrm{Bcl}-2$ family members. ${ }^{31}$ Thereby, it inhibits apoptosis induction by multiple stimuli, including UV irradiation of HeLa cells, ${ }^{32}$ which was used as a positive control. HeLa cells were transduced with Bcl-2- or vector-encoding retrovirus. Stable cell lines were generated, in which differential levels of $\mathrm{Bcl}-2$ expression were clearly detectable by immunoblotting (Figure 3c). UV-induced apoptosis was effectively blocked in Bcl-2-transduced cells (Figure $3 c$ ). In contrast, apoptosis induction by transfected full-length Reaper was as efficient in vector control cells as in Bcl-2-transduced cells. Moreover, the capacity of the $\triangle \mathrm{IBM}$ Reaper mutant to induce apoptosis was not affected by Bcl-2 overexpression. Together, these data reveal a major pathway of Reaper-induced apoptosis in human cells, which does not require the IBM of Reaper, nor mitochondrial permeabilisation by pro-apoptotic $\mathrm{BH} 3-$ domain and Bax/Bak proteins.

\section{$\triangle$ IBM Reaper downregulates XIAP at the protein level, independent of XIAP's ubiquitin ligase activity or proteasomal degradation}

Since full-length Reaper can induce apoptosis by affecting IAP function, we first examined to what extent the $\triangle$ IBM mutant was able to do so. To examine whether deletion of the seven amino-terminal residues of Reaper indeed resulted in loss of interaction with IAPs, we checked the interaction of human XIAP with Reaper and $\triangle$ IBM Reaper. COS cells were transfected with Myc-tagged XIAP alone or in combination with Reaper-GFP or $\triangle I B M$ Reaper-GFP. Interaction between XIAP and Reaper was monitored by anti-GFP immunoblotting of anti-Myc (XIAP) immunoprecipitates. Clearly, full-length Reaper, but not the $\triangle I B M$ mutant interacted with XIAP. Immunoblotting of total cell lysates confirmed expression of both Reaper proteins (Figure 4a). In cells transfected with fulllength Reaper, XIAP levels were downregulated, as determined by anti-Myc immunoblotting of total cell lysates and anti-Myc immunoprecipitates. Despite its failure to interact with XIAP, $\triangle \mathrm{IBM}$ Reaper, like full-length Reaper, downregulated XIAP protein levels.

We next investigated whether the downregulation of XIAP protein levels by Reaper and $\triangle I B M$ Reaper was due to proteasome-mediated degradation of XIAP. To this end, we

Figure 2 Caspase activation and apoptosis induction following Reaper or $\Delta$ IBM Reaper expression. HeLa cells were transfected with Reaper-GFP, $\Delta$ IBM Reaper-GFP or empty vector. As a control for caspase activation and apoptosis induction, cells were stimulated with UV light. At $48 \mathrm{~h}$ after transfection or $8 \mathrm{~h}$ after irradiation with UV light, cells were examined. (a) Apoptosis was scored microscopically, on the basis of morphological features as outlined in the Materials and methods section. In case of transfected cells, apoptosis is expressed as the percentage of apoptotic cells of the total number of green fluorescent (Reaper expressing) cells examined. In nontransfected cells that were treated with UV light or mock-incubated, apoptosis is expressed as the percentage of apoptotic cells of the total number of cells stained with Hoechst 33342. Results are derived from three independent experiments and shown is the mean percentage apoptosis \pm S.D. (b) Caspase activation was monitored by immunoblotting of the total cell population used for transfection, of which about $30 \%$ expressed Reaper proteins. Proteins derived from cell lysates were probed with anti-GFP antibody to detect the chimeric Reaper proteins and with antibodies to endogenous Caspase-7, PARP, or actin, as indicated 

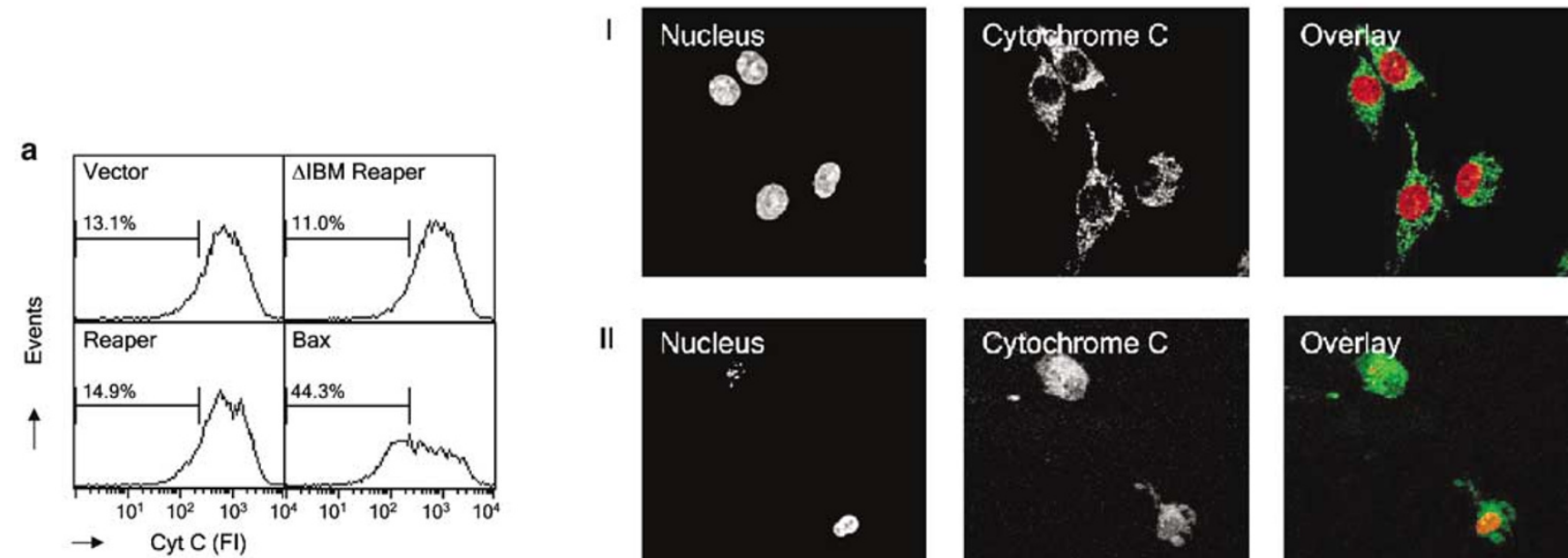

II
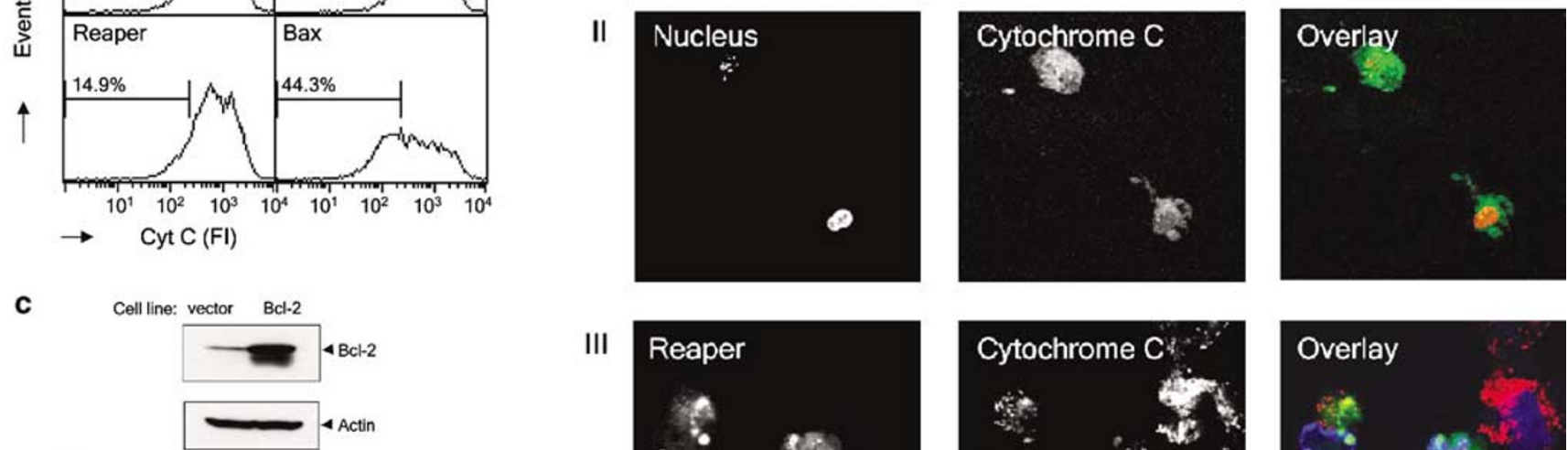

III
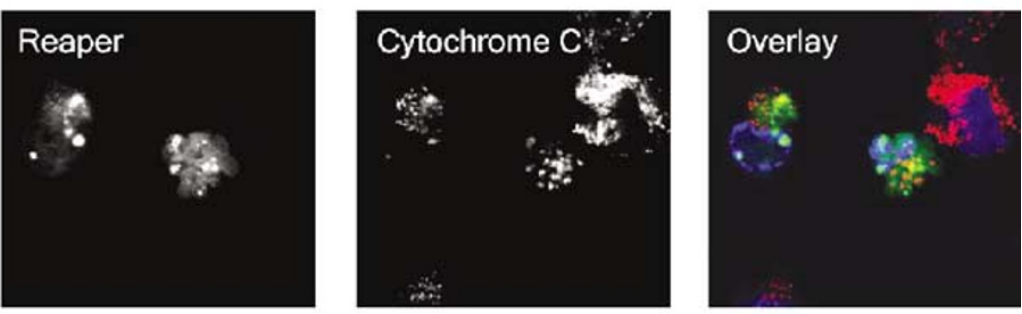

IV
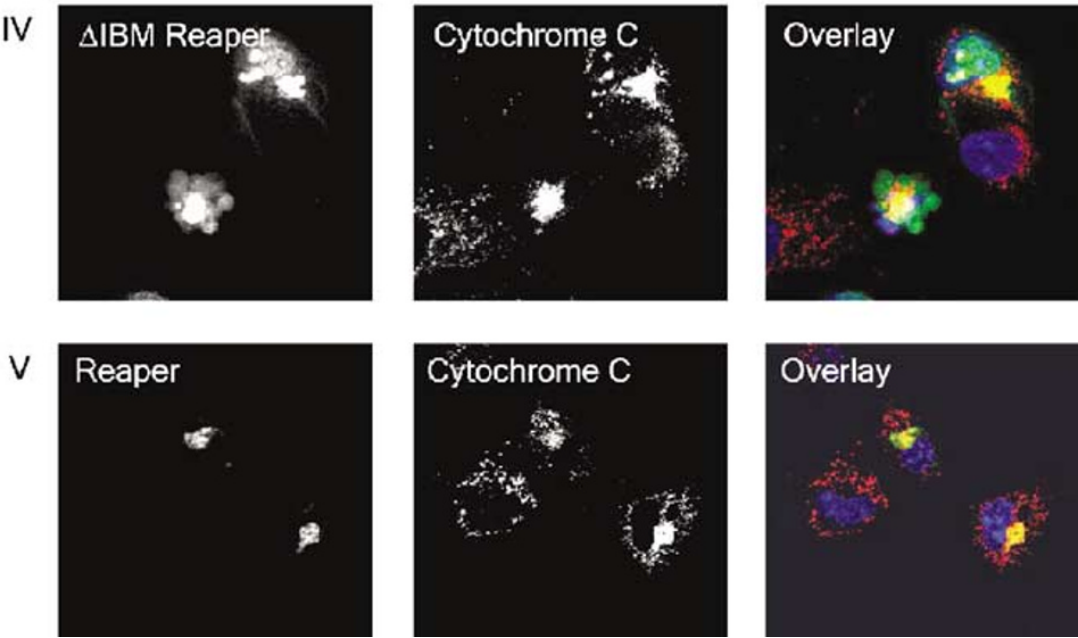

Figure 3 Analysis of mitochondrial participation in Reaper-mediated apoptosis. HeLa cells were transfected with Reaper-GFP, $\triangle$ IBM Reaper-GFP or GFP-histone and analysed $48 \mathrm{~h}$ later. As control for Cyt c release, cells were either transfected with HA-Bax and GFP-histone (to serve as a transfection marker) or stimulated with UV light for $8 \mathrm{~h}$. (a) FACS analysis of Cyt $c$ release, for which cells were permeabilised with digitonin, fixed and stained with anti-Cyt $c \mathrm{mAb}$ and fluorescent secondary antibody. Cyt $c$ content was specifically analysed in the transfected population by gating around the GFP positive (Reaper- or Histone-expressing) population. The percentage of cells that displayed reduced Cyt $c$ content as determined by applying the indicated gate is shown. (b) Confocal microscopy, for which cells were fixed and stained with anti-Cyt $c$ mAb and fluorescent secondary antibody. Nuclei were stained with TO-PRO-3 iodide. Panel I shows control cells, II shows cells treated with UV light, III shows Reaper-GFP-expressing cells, IV shows $\triangle \mathrm{IBM}$ Reaper-GFP-expressing cells and V shows Reaper-GFP-expressing cells cultured in the presence of ZVAD. In the overlay of panels III, IV and V Reaper is shown in green, Cyt $c$ in red and nuclei in blue. (c) Effect of Bcl-2 expression on Reaper's capacity to kill. HeLa cells were stably transduced with retrovirus encoding empty vector or human Bcl-2. Cell lysate proteins were probed by immunoblotting with either anti-Bcl-2 antibody or anti-actin antibody (inset). Transduced cells were transiently transfected with Reaper-GFP or $\Delta \mathrm{IBM}$ Reaper-GFP and analysed $48 \mathrm{~h}$ later for apoptosis induction. Results are derived from three independent experiments and the mean percentage apoptosis \pm S.D. is shown

expressed XIAP and Reaper or $\triangle \mathrm{IBM}$ Reaper in COS cells, which were cultured in the presence or absence of proteasome inhibitor MG132. XIAP protein levels in cells transfected with Myc-XIAP ( + empty vector) were strongly upregulated following incubation with MG132, confirming the inhibitor's functionality in this assay (Figure $4 \mathrm{~b}$, left panel). XIAP levels in cells expressing full-length Reaper greatly increased following proteasome inhibition. However, they were not fully restored 
to the levels seen in cells lacking Reaper expression. This result indicates that full-length Reaper downregulates XIAP levels in part by a proteasome-dependent mechanism. Expression of Reaper itself also significantly increased following proteasome inhibition in XIAP-expressing cells, indicating that full-length Reaper was also targeted for

a
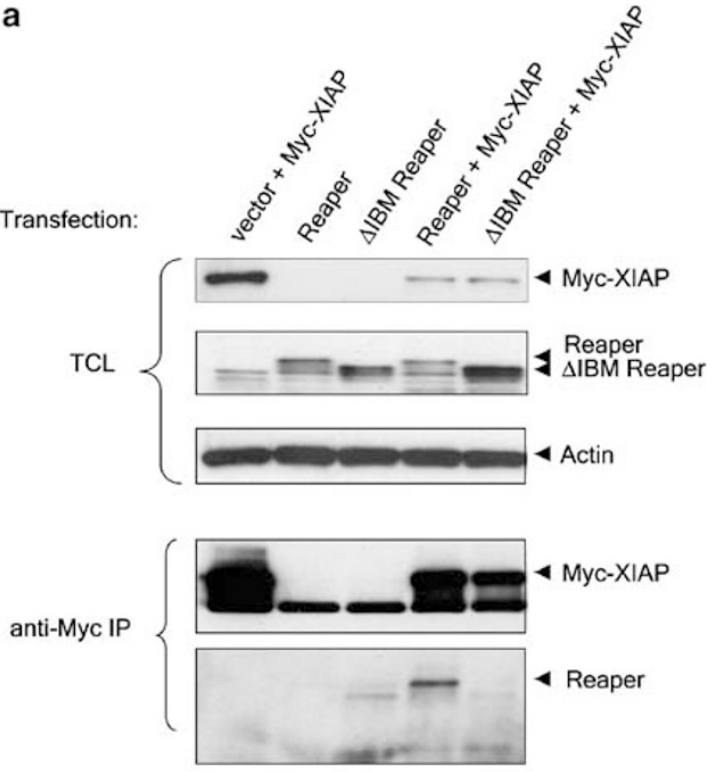

b
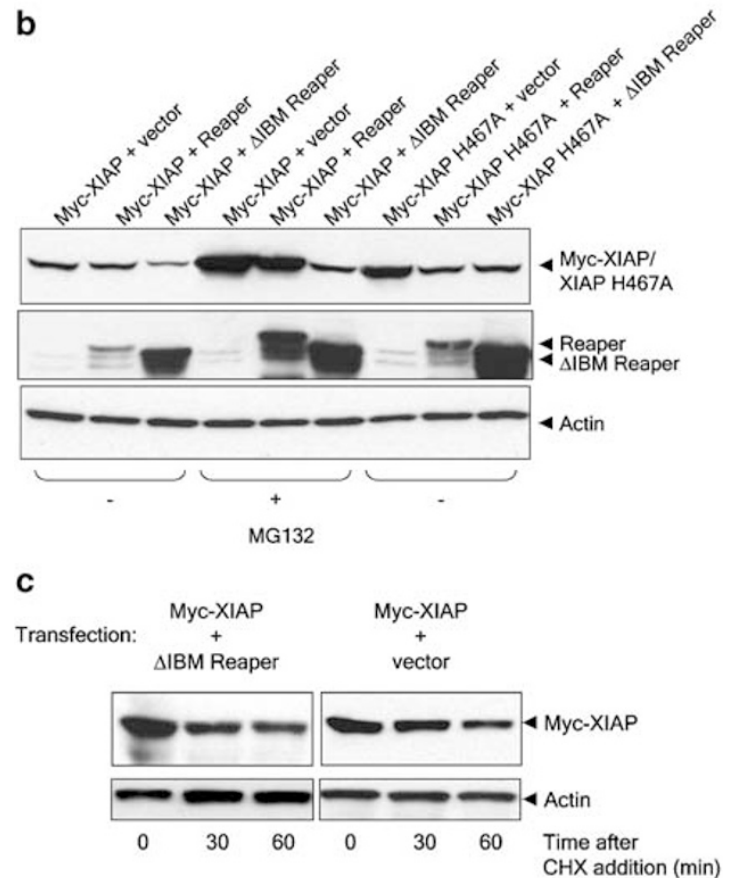

d

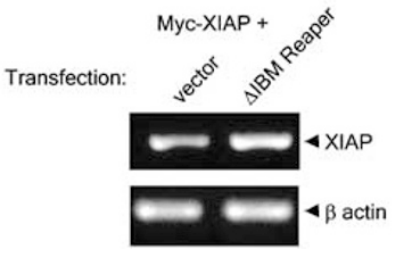

proteasomal degradation in this setting. This is in agreement with a recent report. ${ }^{33}$ Interestingly, proteasome inhibition did not at all affect the ability of $\triangle \mathrm{IBM}$ Reaper to down-regulate XIAP protein levels (Figure 4b, left panel). Also, $\Delta$ IBM Reaper was not subject to proteasome-mediated degradation. Next, we determined whether the ubiquitin ligase activity of XIAP was required for its downregulation by Reaper or $\triangle \mathrm{IBM}$ Reaper. COS cells were transfected with a XIAP mutant, which had been rendered ubiquitin ligase-deficient by a H467A substitution in the Ring finger. ${ }^{9}$ Reaper downregulated XIAP protein levels despite the H467A mutation and $\triangle \mathrm{IBM}$ Reaper did so even more dramatically (Figure 4b, right panel). Collectively, these data show that Reaper can downregulate XIAP by two distinct mechanisms in mammalian cells. One is reliant upon its binding to XIAP and requires XIAP ubiquitin ligase activity as well as proteasome activity. In this pathway, Reaper binds to XIAP, is presumably ubiquitinated by it and as a consequence degraded by the proteasome. XIAP itself follows the same route. The other pathway, which is the sole one employed by $\triangle$ IBM Reaper, does not involve any of these processes.

Since the pro-apoptotic activity of Reaper in human cells appeared to be independent of its IBM, we focused in the next experiments on the mechanism of action of $\triangle \mathrm{IBM}$ Reaper. First, we examined whether $\triangle$ IBM Reaper affected the half-life of the XIAP protein, considering that it may influence protein turnover by a mechanism independent of the proteasome. To this end, XIAP was transfected with $\triangle \mathrm{IBM}$ Reaper or vector alone in COS cells. At 2 days after transfection, cycloheximide (CHX) was added in order to block new protein synthesis. Cells were lysed 30 or 60 min later and XIAP expression was analysed by immunoblot. Since $\triangle \mathrm{IBM}$ Reaper suppresses XIAP expression, immunoblots of lysates with and without $\triangle I B M$ Reaper were differentially exposed to similar intensities to enable adequate comparison. XIAP expression gradually decreased within $1 \mathrm{~h}$ following inhibition of protein synthesis when expressed with vector alone (Figure 4c). In the presence of $\triangle \mathrm{IBM}$ Reaper, XIAP displayed identical kinetics of

Figure 4 Reaper downregulates XIAP expression at the protein level by two independent mechanisms. (a) COS-7 cells were transfected with Myc-tagged human XIAP together with empty vector, Reaper-GFP or $\triangle \mathrm{IBM}$ Reaper-GFP. At $48 \mathrm{~h}$ post-transfection, TCL were prepared and analysed directly for protein expression levels or subjected to immunoprecipitation (IP) followed by immunoblotting. Reaper proteins were detected with anti-GFP antibody, XIAP with anti-Myc mAb and actin with specific antibody. (b) Cells were transfected with Myc-XIAP or a Myc-tagged ubiquitin ligase defective XIAP mutant (H467A) together with empty vector, Reaper-GFP or $\triangle$ IBM Reaper-GFP. In the case of Myc-XIAP transfected cells, cells were treated with or without the proteasome inhibitor MG132 for $6 \mathrm{~h}$ prior to lysis. At $48 \mathrm{~h}$ post-transfection, cell lysates were prepared and analysed directly for protein levels by immunoblotting with antiMyc, anti-GFP or anti-actin antibody. (c) To measure protein stability, COS-7 cells were transfected with Myc-XIAP together with empty vector or $\triangle \mathrm{IBM}$ Reaper-GFP. CHX was added at $48 \mathrm{~h}$ post-transfection. At the indicated times following $\mathrm{CHX}$ addition, cells were lysed and analysed directly for protein expression levels. Blots were probed with anti-Myc mAb to detect XIAP or antiactin $\mathrm{mAb}$ to serve as a loading control. The blot with $\triangle \mathrm{B} B \mathrm{~B}$ Reaper samples was exposed longer than the blot with vector samples to obtain similar intensities of the XIAP signals. (d) To measure mRNA levels COS-7 cells were transfected with Myc-XIAP together with empty vector or $\triangle \mathrm{IBM}$ Reaper-GFP. At $48 \mathrm{~h}$ posttransfection RNA was isolated and subject to semiquantitative RT-PCR using primers specific for human XIAP and $\beta$ actin. PCR products were resolved on an agarose gel and visualised by ethidium bromide staining 
disappearance, indicating that $\triangle \mathrm{IBM}$ Reaper does not affect XIAP stability.

To examine whether the effect of $\triangle$ IBM Reaper on XIAP protein expression was exerted at the level of transcription or mRNA stability, we monitored XIAP transcripts by semiquantitative RT-PCR (Figure 4d). COS cells were transfected with XIAP together with $\triangle \mathrm{IBM}$ Reaper or vector alone. At 2 days after transfection, RT-PCR analysis of XIAP and $\beta$ actin mRNA levels was performed. This analysis revealed no effect of $\triangle$ IBM Reaper on XIAP transcript levels.

In conclusion, full-length Reaper downregulates XIAP in human cells in part by binding to it and stimulating its proteasome-mediated degradation, which is dependent on XIAP's ubiquitin ligase function. In addition, however, Reaper can also downregulate XIAP in human cells independent of proteasomal degradation. It does so at the protein level and leaves transcription unaffected. This alternative mechanism does not require the IBM and is highly effective in human cells.

\section{Reaper and $\triangle \mathrm{IBM}$ Reaper globally suppress protein synthesis}

It has recently been described that Reaper can affect protein expression by a general suppression of protein translation, as demonstrated in cell extracts in vitro and in Xenopus oocytes. ${ }^{14,15}$ Our collective data argued that the alternative mechanism of action of Reaper in human cells likewise involved inhibition of protein translation. Metabolic labelling experiments indicated that in the presence of $\triangle \mathrm{IBM}$ Reaper, new synthesis of XIAP was impeded (results not shown). Next, we determined its effect on proteins other than XIAP. To this end, cells were transfected with constructs encoding various proteins, that is, apoptosis-inducing factor (AIF), phosphatidylinositol (PIP) kinase and survivin, alone or together with Reaper or $\triangle \mathrm{IBM}$ Reaper. At 2 days after transfection, expression levels of these proteins were analysed by immunoblot (Figure 5a). Reaper and $\Delta \mathrm{IBM}$ Reaper downregulated expression of each coexpressed protein, indicating that their effects are not specific for XIAP and suggesting that they indeed affect protein expression in a global sense. In a separate experiment, addition of the caspase inhibitor ZVAD-fmk did not affect the ability of Reaper or $\triangle \mathrm{IBM}$ Reaper to suppress AIF expression, demonstrating

Figure 5 Reaper suppresses global protein synthesis in mammalian cells. (a) 293T cells were transfected with Myc-tagged PIP kinase together with empty vector, Reaper-GFP or $\triangle \mathrm{IBM}$ Reaper-GFP. COS-7 cells were transfected with Myc-tagged human AIF or FLAG-tagged survivin together with empty vector, Reaper-GFP or $\Delta$ IBM Reaper-GFP. At $48 \mathrm{~h}$ post-transfection, cell lysates were prepared and analysed directly for protein expression levels. Blots were probed with anti-GFP antibody to detect Reaper fusion proteins, anti-Myc or anti-FLAG $\mathrm{mAb}$ to detect tagged proteins, or anti-actin mAb to serve as a loading control. A nonspecific protein (NS) detected with the FLAG antibody was used as a loading control where indicated (b) HeLa cells were transfected with vector, Reaper-GFP or $\triangle \mathrm{IBM}$ Reaper-GFP as indicated. Cells were cultured with ZVAD-fmk. At 1 day after transfection, cells were sorted on the basis of GFP expression and futher cultured in the presence of ZVAD-fmk. The following day, equal numbers of cells were labelled with $\left[{ }^{35} \mathrm{~S}\right]$-methionine/cysteine mixture for $1 \mathrm{~h}$. Cell lysates were prepared and either separated by SDS-PAGE or subject to TCA precipitation. Radiolabelled proteins were detected by autoradiography or quantitated by scintillation counting that this effect is not a consequence of caspase activity (data not shown).

To further examine this mechanism, we performed metabolic labelling experiments and monitored the overall protein synthesis. Empty vector-GFP, Reaper-GFP and $\triangle$ IBM Reaper-GFP were transfected into HeLa cells, which were cultured in the presence of ZVAD-fmk and sorted on the basis of equal levels of GFP expression $24 \mathrm{~h}$ after transfection. After 1 day,

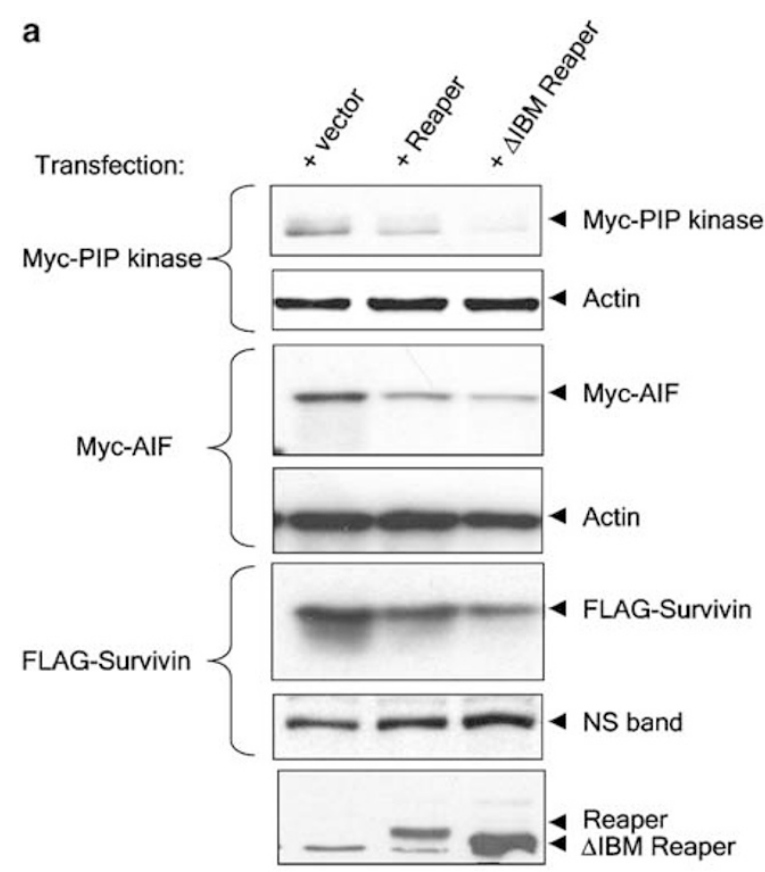

b

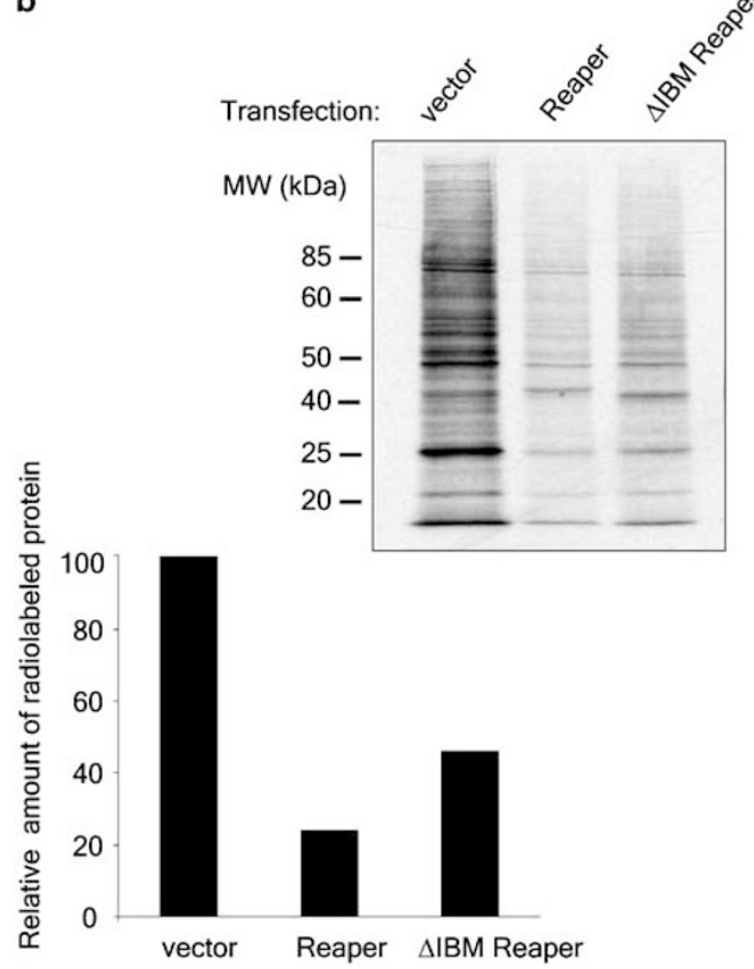



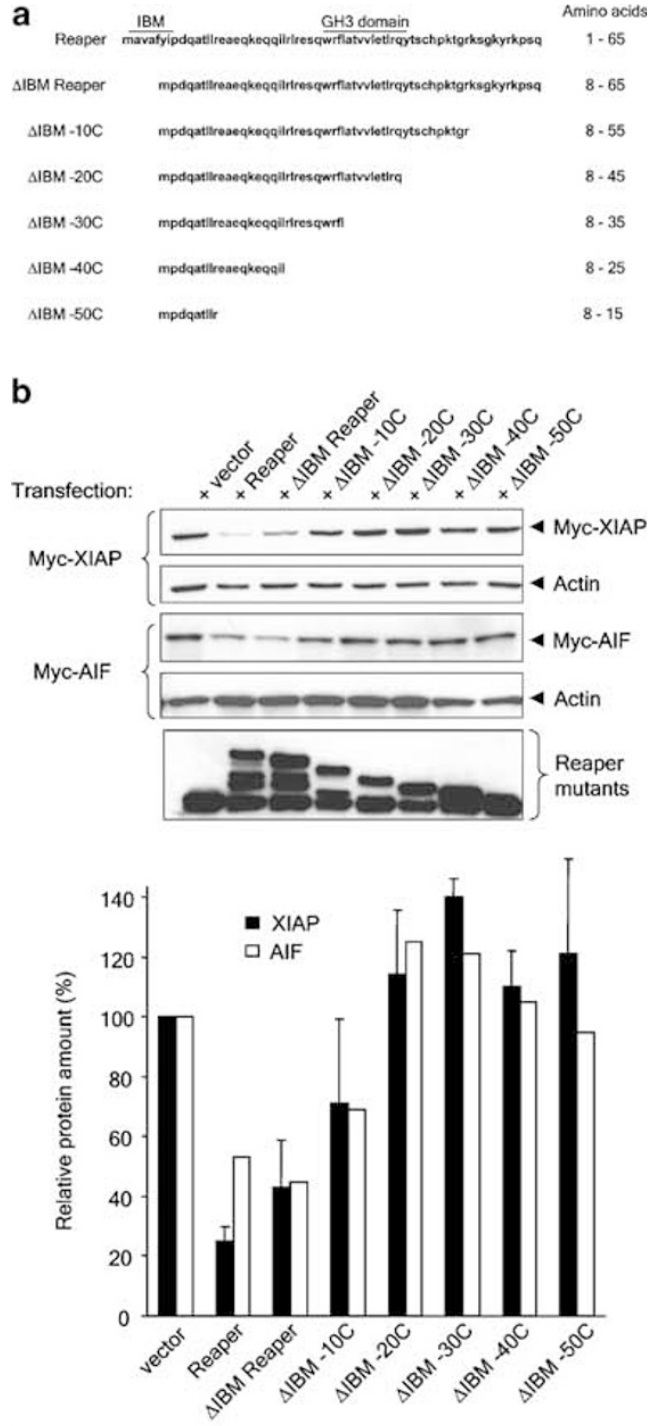

C

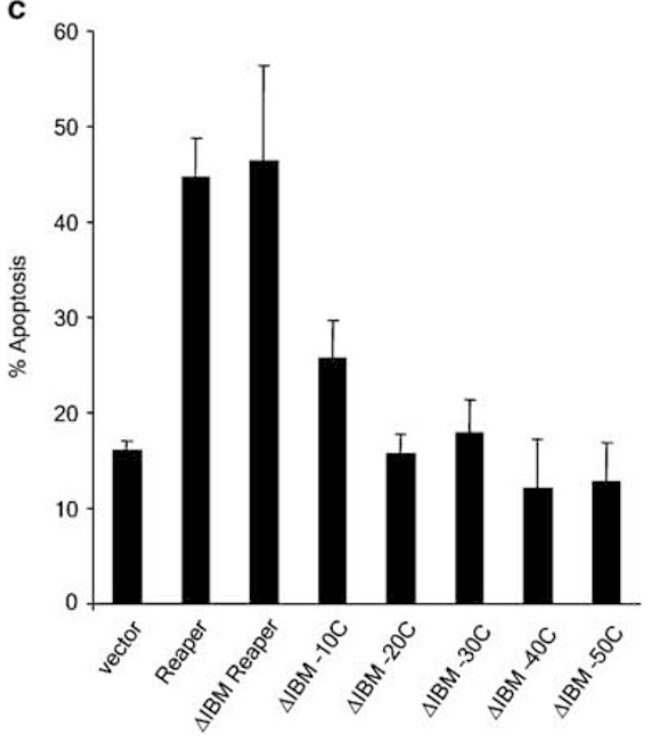

equal numbers of cells from each transfected line were labelled for $1 \mathrm{~h}$ with ${ }^{35} \mathrm{~S}$ methionine/cysteine and analysed for the presence of radiolabelled protein by SDS-PAGE of total cell lysates and scintillation counting of total TCA-precipitated protein derived from cell lysates. Both Reaper and $\triangle \mathrm{IBM}$ Reaper efficiently reduced radiolabelled protein levels detectable by autoradiography. Scintillation counting of TCAprecipitated radiolabelled protein allowed a quantitative measure and reproducibly showed two or more fold reduction in the overall levels of radiolabelled protein by Reaper and $\Delta$ IBM Reaper. The impact on protein levels within $1 \mathrm{~h}$ after synthesis, combined with our earlier findings that the alternative mechanism of protein downregulation does not involve effects on protein stability or mRNA levels, argues that Reaper expression in human cells leads to a generalised suppression of protein translation by a mechanism that is independent of Reaper's IBM. It is also independent of caspase activation and therefore not a consequence of activation of the apoptotic machinery.

\section{Removing Reaper's ability to inhibit protein synthesis blocks its ability to induce apoptosis}

To map the region in Reaper that is essential for its capacity to inhibit protein synthesis, we made progressive 10 amino-acid carboxy-terminal deletions in $\triangle I B M$ Reaper-GFP (Figure 6a). We next investigated the ability of these deletion mutants to downregulate protein levels. COS cells were transfected with GFP-fusion proteins of Reaper, $\triangle \mathrm{IBM}$ Reaper or mutants thereof, together with XIAP or AIF. Relative levels of AIF and XIAP protein were determined 2 days after transfection by immunoblotting and quantified by densitometry. As expected, both Reaper and $\triangle \mathrm{IBM}$ Reaper significantly inhibited XIAP and AIF protein expression. Removal of the carboxy-terminal 10 amino acids from $\triangle I B M$ Reaper reduced but did not abolish its ability to suppress protein expression (Figure 6b). Removal of an additional 10 carboxy-terminal residues fully abrogated the ability of $\triangle I B M$ Reaper to suppress XIAP and AIF protein levels. Quantitative data depicted in the lower panel of Figure $6 \mathrm{~b}$ show that effects of Reaper and mutants on XIAP protein levels were reproducible in independent experiments. Variability in the effectiveness of Reaper and $\triangle I B M$ Reaper to repress XIAP levels were related to differences in their

Figure 6 Removing Reaper's ability to inhibit translation blocks its proapoptotic activity in HeLa cells. (a) Schematic diagram of Reaper, $\triangle$ IBM Reaper and the various $\Delta \mathrm{IBM}$ Reaper carboxy-terminal deletion mutants. (b) COS-7 cells were transfected with Reaper, $\triangle \mathrm{IBM}$ Reaper and the $\triangle \mathrm{IBM}$ Reaper deletion mutants together with either Myc-XIAP or Myc-AIF. At $48 \mathrm{~h}$ post-transfection, cells were lysed and analysed directly for protein expression levels by immunoblotting. Blots were probed with anti-GFP antibody to detect Reaper fusion proteins, anti-Myc $\mathrm{mAb}$ to detect Myc-tagged proteins or anti-actin mAb to serve as a loading control. ECL signals for XIAP or AIF were quantitated by densitometry. XIAP and AIF levels were normalised to the actin signal and are expressed relative to the levels in XIAP or AIF in cells transfected with vector alone. Values for XIAP levels are means and standard deviations derived from three independent experiments. (c) HeLa cells were transfected with Reaper, $\Delta \mathrm{IBM}$ Reaper or the various $\triangle \mathrm{IBM}$ Reaper carboxy-terminal deletion constructs. At $48 \mathrm{~h}$ post-transfection, cells were examined microscopically for apoptotic features. Results are derived from three independent experiments and the mean percentage apoptosis \pm S.D is shown 
expression levels in different transfection experiments. We conclude that the carboxy-terminal 20 amino acids of Reaper play a key role in inhibition of protein synthesis.

Next, we examined whether Reaper's ability to cause apoptosis in mammalian cells could be linked to its ability to downregulate global protein synthesis. HeLa cells were transfected with Reaper, $\triangle \mathrm{IBM}$ Reaper and the various deletion mutants thereof. After 2 days later, the incidence of apoptosis in Reaper-expressing cells was determined (Figure 6c). As before (Figure 2a), expression of Reaper and $\triangle$ IBM Reaper caused apoptosis in HeLa cells to a similar degree. Removal of the carboxy-terminal 10 amino acids reduced but did not abolish Reaper's ability to cause apoptosis. Deleting the carboxy-terminal 20 amino acids completely abolished Reaper's pro-apoptotic activity. Together, these data suggest that Reaper's ability to induce apoptosis in mammalian cells is linked with its ability to inhibit protein synthesis.

\section{Discussion}

In this study, we have investigated the mechanism by which the Drosophila protein Reaper induces apoptosis in human cells. Specifically, we have examined the function of a Reaper mutant, which can no longer kill cells via the displacement of IAPs from caspases and concomitant rescue of caspases from proteasomal degradation. This $\triangle I B M$ mutant was found to retain most of its pro-apoptotic activity in human cells, as compared to full-length Reaper, indicating that there exists a major alternative pathway for Reaper to activate caspases, which does not require its IBM.

We investigated whether this pathway required the induction of mitochondrial permeability and the release of mediators, such as Cyt $c$. Evidence for such a Reaper pathway has been found in an in vitro system. ${ }^{28-30}$ However, we found no evidence for a release of Cyt $c$ from mitochondria in Reaperexpressing cells. Moreover, apoptosis mediated by full-length or $\Delta \mathrm{IBM}$ Reaper was not affected by increased $\mathrm{Bcl}-2$ protein levels, which effectively blocked UV-induced apoptosis. Collectively, our data argue that Drosophila Reaper can activate an evolutionary conserved pathway in human cells, which leads to caspase activation and apoptosis, but is independent of mitochondrial permeabilisation by $\mathrm{BH} 3$ domain-only $\mathrm{Bcl}-2$ proteins and their relatives Bax and Bak, as well as Cyt $c$ release.

The capacity of Reaper to bring about Cyt $c$ release has not previously been assessed in mammalian cells. It has been reported that in Drosophila cells Cyt $c$ is not released from mitochondria during apoptosis, also not upon expression of the pro-apoptotic Bcl-2 family member DEBCL. Cyt $c$ does, however, adopt an altered conformation during the apoptotic process, also in response to Reaper expression. ${ }^{34,35}$ Caspases were seen to cluster around the mitochondria and mitochondria from apoptotic cells could trigger effector caspase function in vitro, arguing that some active upstream component was associated with them. ${ }^{34,35}$ Drosophila cells express a homologue of the mammalian Apaf-1 scaffold protein, which can bind Cyt $c$ in vitro. Moreover, in extracts from Drosophila cells, exogenous Cyt $c$ can promote caspase activation, dependent on endogenous Apaf-1 expression. ${ }^{36,37}$ These findings argue that Drosophila employs the equivalent of the mammalian apoptosome to initiate caspase activation. However, they do not prove that Cyt $c$ is a requisite in this pathway in Drosophila. The altered conformation of Cyt $c$ in fact depended on caspase activity. ${ }^{34}$ Moreover, suppression of Drosophila Cyt $c$ expression by RNA interference had no effect on the pro-apoptotic activity of Reaper. ${ }^{25}$ Lack of the Drosophila Apaf-1 homologue, though, clearly compromised developmental apoptosis induced by Reaper and relatives. $^{36,37}$

Drosophila does express two Bcl-2 family members, which are both pro-apoptotic. ${ }^{3}$ Their mechanism of action is presently unclear. Expression of mammalian Bcl-2 in Drosophila has yielded contradictory results. One study showed that human $\mathrm{Bcl}-2$ or $\mathrm{Bcl}-\mathrm{xL}$ has no effect on Reaper-mediated apoptosis in a Drosophila cell line. ${ }^{38}$ In contrast, transgenic human $\mathrm{Bcl}-2$ has recently been shown to inhibit Reaperinduced wing phenotypes in Drosophila. ${ }^{39}$ However, in this study, Bcl-2 suppressed Reaper expression, which may explain its inhibitory effect. In short, there is thus far no compelling evidence that mitochondria are permeabilised during apoptosis signalling in insect cells and the pathways in which the Apaf and $\mathrm{Bcl}-2$ homologues act are as yet undefined.

The function of the Reaper-related Grim protein has been studied quite extensively in mammalian cells. It was originally reported that Grim-induced apoptosis in 3T3 fibroblasts could be inhibited by Bcl-2. ${ }^{40}$ However, in a recent study, the same authors provide evidence that Grim kills mammalian cells via a novel pathway that involves mitochondrial permeabilisation independent of Bax/Bak proteins. The authors suggest that the effect of $\mathrm{Bcl}-2$ observed previously might have been an indirect one. ${ }^{27}$ The GH3 domain of Grim targets this protein to mitochondria and is sufficient to induce Cyt $c$ release in mammalian cells. ${ }^{27}$ In the absence of caspase activation, Grim adopts a perinuclear localisation and co-localises with mitochondria in apoptosis-prone cells.

Residues 32-46 in Reaper are also predicted to form a GH3-domain $\alpha$ helix. ${ }^{26}$ It has recently been reported that in insect cells the $\mathrm{GH} 3$ domain is required for localisation of Reaper to mitochondria. ${ }^{41}$ However, in mammalian cells, we do not find constitutive co-localisation of Reaper with mitochondria. We did observe that full-length and $\triangle \mathrm{IBM}$ Reaper redistributed from the cytosol to regions close to the nucleus throughout the apoptotic process, which resulted in a partial co-localisation with mitochondria. The co-localisation of Reaper and mitochondria in transfected 293 cells noted by Olson et $a{ }^{41}$ may reflect a similar situation.

Despite the shared presence of a GH3 domain in Grim and Reaper, their mechanism of action in mammalian cells is distinct. Our study excludes that Reaper kills mammalian cells by inducing mitochondrial permeability, either by a $\mathrm{Bcl}-2$ dependent or -independent mechanism. Possibly, the GH3 domain of Reaper has a different mechanism of action than the $\mathrm{GH} 3$ domain of Grim in the context of the additional unique sequences of the Reaper protein. While the 20 -amino-acid Cterminal deletion included in our study might just affect the structure of the $\mathrm{GH} 3$ domain, deletion of residues 55-65 does not. Nevertheless, this deletion strongly reduces Reaper's 
pro-apoptotic activity, arguing that regions other than the $\mathrm{GH} 3$ domain are critical for cell death induction. Also in Grim, additional sequences apart from the IBM and GH3 domains may contribute to apoptosis induction in mammalian cells, since deletion of these domains did not fully abrogate Grim's pro-apoptotic activity. ${ }^{27}$

In the Xenopus oocyte system, evidence indicates that Reaper can activate caspases via a mitochondrial pathway. It does not act on mitochondria directly, but needs Scythe and Scythe-associated undefined mediators. ${ }^{28-30}$ Reaper-induced Cyt $c$ release was not blocked by $z V A D$ in this system. ${ }^{28}$ However, this does not rule out that in Xenopus oocyte extracts, Reaper activates a zVAD non-inhibitable caspase and in this way initiates a feed-back amplification loop for effector caspase activation via the mitochondria. Such a scenario would reconcile our findings with the data from these studies. We found that human Scythe ${ }^{42}$ localised exclusively in the nucleus (results not shown), in accordance with a previous study that defined a nuclear localisation signal in this protein. ${ }^{43}$ We did not detect any physical or functional interaction of Reaper or Scythe following their co-expression in HeLa cells. It will be of interest to test the requirement of Scythe for Reaper-induced apoptosis in both Drosophila and mammalian cells by RNA interference.

Clearly, Reaper can induce apoptosis in human cells, independent of its IBM. If this mechanism does not involve caspase activation via the mitochondria, what does it entail? Recently, Reaper and Grim (but not Hid) were shown to possess the capacity to generally suppress protein translation. This was demonstrated by adding these molecules to in vitro rabbit reticulocyte lysate translation systems. Yield of IAPs, but also of completely unrelated proteins, was significantly decreased by Reaper or Grim. A GST fusion protein of Reaper lacking the IBM retained this capacity. ${ }^{14,15}$ Our findings indicate that this newly recognized pathway can operate in mammalian cells. It has recently been reported that the NSs protein from Bunyavirus has structural homology with Reaper within the GH3 region, as well as amino- and carboxyterminal from it. ${ }^{44}$ It shares with Reaper the capacity to inhibit translation, as well as the capacity to induce Cyt $c$ release and caspase activation in Xenopus egg extracts. Structurally, these two functions were separable: GH3 domain point mutations disrupted the pro-apoptotic activity in vitro while leaving translational inhibition intact. In our study, deletion of residues 55-65 outside the GH3 domain strongly impaired both translational inhibition and apoptosis induction in vivo. These data suggest that translational inhibition might be instrumental in apoptosis induction. HeLa cells are killed to a significant extent by inhibition of protein synthesis with cycloheximide within a $48 \mathrm{~h}$ time frame (up to $35 \%$, results not shown). However, apoptosis incidence was repeatedly somewhat higher upon Reaper expression, suggesting that additional features of Reaper play a role. Although the carboxy-terminal 20 amino acids of Reaper were critical for its capacity to inhibit protein synthesis, they appeared not sufficient, since a GFP-fusion protein containing only these residues of Reaper did not display this activity. It also could not induce apoptosis (results not shown). Further mutational analysis should point out whether apoptosis induction in vivo and translational inhibition are separable or structurally linked.

\section{Materials and Methods}

\section{Cell culture, apoptosis induction and cell treatments}

The human cervical carcinoma cell line HeLa, $293 \mathrm{~T}$ human embryonic kidney cells, COS-7 African green monkey kidney cells and the $293 \mathrm{~T}$ cellderived packaging cell line Phoenix-Ampho ${ }^{45}$ were grown in Dulbecco's modified medium, supplemented with $8 \%$ fetal calf serum, $2 \mathrm{mM}$ glutamine and antibiotics. Retrovirally transduced HeLa cells were grown in this medium, in the presence of $200 \mu \mathrm{g} / \mathrm{ml}$ Zeocin (Invitrogen). Apoptosis was induced by irradiation with UV light at $18 \mathrm{~mJ} / \mathrm{cm}^{2}$. The pan-caspase inhibitor ZVAD-fmk (Calbiochem) was added at $50 \mu \mathrm{M}$ final concentration at the time of transfection and refreshed $24 \mathrm{~h}$ later. The proteasome inhibitor MG132 (Calbiochem) was added at $50 \mu \mathrm{M} 6 \mathrm{~h}$ prior to cell lysis. Cycloheximide (Sigma) was added at $10 \mu \mathrm{g} / \mathrm{ml}$ for the indicated time periods.

\section{Plasmids}

Full-length Reaper cDNA was provided by Dr. H Steller (Rockefeller University, New York, USA). Reaper, $\triangle \mathrm{IBM}$ Reaper (lacking the first seven amino-terminal amino acids) and $\triangle I B M$ Reaper carboxy-terminal deletion mutants were cloned into the eGFPN1 plasmid (Clontech) by PCR-based subcloning. Cloning into eGFPN1 fuses the cDNA at the carboxy-terminus to GFP. Human XIAP cDNA was a gift from Dr. R Takahashi (RIKEN-Brain Institute, Wako City, Saitama, Japan). It was subcloned into pMT2SM-Myc by introducing suitable restriction sites by PCR. Plasmid pMT2SM-Myc allows the protein to be amino-terminally Myc-tagged. ${ }^{46}$ The ubiquitin ligase defective XIAP mutant $(\mathrm{H} 467 \mathrm{~A})$ was made by site-directed mutagenesis of the human XIAP CDNA (histidine 467 changed to alanine) as previously described. ${ }^{9}$ pCR3 vector encoding amino-terminally FLAGtagged human Survivin was provided by Dr. S Lens (The Netherlands Cancer Institute, Amsterdam, Netherlands). pcDNA3 encoding HA-tagged mouse Bax was provided by Dr. $\mathrm{H}$ Brady (National Institute for Medical Research, London, UK). The plasmid encoding histone 2B-GFP was a kind gift of Dr. R Agami (The Netherlands Cancer Institute, Amsterdam, The Netherlands) and has been described previously. ${ }^{47}$ The cDNA encoding human AIF was obtained from the NIH mammalian gene collection (number 4548458) and was cloned into pMT2SM-Myc by PCRbased subcloning. Retroviral vector LZRS-Bcl-2-IRES-Zeo/pBR encoding human Bcl-2 and the corresponding empty vector have been described previously. ${ }^{46}$ Plasmid pMT2SM encoding Myc-tagged human type I $\alpha$ PIP kinase was provided by Dr. N Divecha (The Netherlands Cancer Institute, Amsterdam, The Netherlands). All sequences were verified by dideoxynucleotide sequencing.

\section{Transfections and retroviral transductions}

For transient transfection of HeLa cells, cells were seeded in six well plates at $1 \times 10^{5}$ cells per well. When intended for examination by confocal laser microscopy, cells were grown in these wells on glass coverslips. For FACS analysis of Cyt c release, $5 \times 10^{5} \mathrm{HeLa}$ cells were seeded in $10 \mathrm{~cm}$ dishes. After overnight culture, cells were transfected in the presence of FuGENE 6 transfection reagent according to instructions of the manufacturer (Roche Molecular Biochemicals). In case of HA-Bax transfection, eGFPHistone was co-transfected to serve as a transfection marker at a ratio of $10: 1$ Bax over GFP-Histone. For analysis of protein synthesis, HeLa cells were seeded in $10 \mathrm{~cm}$ dishes at $1 \times 10^{6}$ cells per dish. Cells were transfected the following day and cultured in ZVAD-fmk. After overnight culture, transfected cells were detached and selected for GFP expression using a MoFlo high-speed cell sorter (Cytomation, Fort Collins, CO, USA). 
$293 \mathrm{~T}$ cells were seeded in $10 \mathrm{~cm}$ dishes at $1 \times 10^{6}$ cells per dish. After overnight culture, cells were transfected with FuGENE 6 reagent. COS-7 cells were seeded in six well plates at $1 \times 10^{5}$ cells per well. After overnight culture, cells were transfected by the DEAE-Dextran method. Retroviral particles were produced by transfection of retroviral constructs into the Phoenix-Ampho packaging cell line as described. ${ }^{45}$ For retroviral transduction, HeLa cells were seeded in six well plates at $1 \times 10^{5}$ per well and cultured overnight in virus-containing supernatant of the packaging line, in the presence of $10 \mu \mathrm{g} / \mathrm{ml}$ Dotap (Roche). Transduced cells were selected by culturing in the presence of Zeocin.

\section{Apoptosis assay}

Cells were assessed for apoptosis by cellular and nuclear morphological criteria. Cells were determined, by fluorescence and light microscopy, as being apoptotic if they displayed a rounded or blebbed cellular morphology coupled with condensed chromatin or fragmented nuclei. Cells expressing Reaper-GFP chimeras were stained with Hoechst 33342 (Molecular Probes) at $1 \mu \mathrm{M}$ in medium to assess nuclear morphology. Approximately 200 green fluorescent cells were counted in total from three random fields.

\section{FACS analysis of Cyt $c$ release}

Cells were analysed for Cyt $c$ content by intracellular fluorescence of digitonin-permeabilised, fixed cells, according to a previously published protocol, ${ }^{48}$ using anti-Cyt $c$ mAb 6H2.B4. (BD PharMingen) at 1:100 dilution and a Cy5-conjugated goat anti-mouse Ig antibody (Molecular Probes) at $1: 100$ dilution. Cells were analysed using a FACScalibur and CellQuest software (Becton Dickinson). Cyt $c$ content was analysed specifically in transfected cells by gating the GFP-positive population.

\section{Cell lysis and immunoblotting}

Cells were lysed in immunoprecipitation buffer $(50 \mathrm{mM}$ Tris- $\mathrm{HCl} \mathrm{pH} 7.4$. with $1 \%$ Nonidet P-40, $150 \mathrm{mM} \mathrm{NaCl}, 1 \mathrm{mM}$ EDTA, $1 \mathrm{mM}$ PMSF and Complete protease inhibitors (Roche)). Lysates were cleared by centrifugation at $13.000 \mathrm{~g}$ for $10 \mathrm{~min}$ and analysed for protein content by the Bio-Rad protein assay (Bio-Rad, Muenchen, Germany). An equal amount of protein per sample, as determined by the Bio-Rad protein assay, was separated by electrophoresis on $10 \%$ or $12.5 \%$ SDSpolyacrylamide minigels under reducing conditions and transferred onto nitrocellulose membrane. Following transfer, membranes were incubated for $1 \mathrm{~h}$ at room temperature in Tris-buffered saline (TBS) with $0.05 \% \mathrm{v} / \mathrm{v}$ Tween $20,5 \%$ w/v nonfat dry milk (Nutricia). Membranes were probed with the following antibodies diluted in TBS/Tween 20 with $1 \%$ dry milk: anticaspase 7 (PharMingen, 1:1000), anti-PARP (Cell Signalling Laboratories, $1: 2000)$, anti-human Bcl-2 (Sigma, 1:500), anti-actin (Chemicon 1: 10000), anti-FLAG M2 (Sigma 1:1000), anti-Myc 9E10 (hybridoma supernatant, 1:250) or anti-GFP (1:500 Clontech). Membranes were then washed with TBS/Tween 20 and incubated with the appropriate secondary antibody in TBS/Tween 20 with $1 \%$ dry milk. Membranes were washed again and immunoreactive proteins were visualised by enhanced chemiluminescence (Amersham Pharmacia). Where appropriate, autoradiographs were quantified by densitometry using a Fluorchem 8000 imager (Alpha Innotech Corp., San Leandro, CA, USA).

\section{Immunoprecipitation}

COS cells were lysed in immunoprecipitation buffer. Lysates were cleared by centrifugation at $13000 \mathrm{~g}$ for $10 \mathrm{~min}$ and incubated for $1 \mathrm{~h}$ at $4^{\circ} \mathrm{C}$ with pre-immune rabbit serum and protein G-Sepharose beads (Amersham Pharmacia). Next, lysates were incubated for $4 \mathrm{~h}$ with anti-Myc mAb (9E10) coated on protein G-Sepharose beads. Immunoprecipitated proteins were resolved by gel electrophoresis and detected by autoradiography or immunoblot as described above.

\section{Metabolic labelling and protein translation analysis}

For analysis of protein synthesis, equal numbers of transfected, sorted GFP positive HeLa cells were seeded in six well plates $5 \times 10^{4}$ cells per well). Cells were labelled for $1 \mathrm{~h}$ with $6 \mathrm{MBq}\left[{ }^{35} \mathrm{~S}\right]$-methionine and -cysteine mixture in $1 \mathrm{ml}$ methionine/cysteine-free DMEM (containing serum, glutamine and antibiotics). Cells were lysed in $50 \mu$ immunoprecipitation buffer and lysates cleared by centrifugation at $13000 \mathrm{~g}$ for $10 \mathrm{~min}$. A volume of $10 \mu \mathrm{l}$ of cell lysate was separated by $10 \%$ SDS-PAGE and radiolabelled proteins were detected by autoradiography. The remaining $40 \mu$ l was subjected to TCA precipitation and radiolabelled protein content was quantified by scintillation counting.

\section{RNA isolation and PCR}

RNA was isolated from transfected HeLa cells $\left(1 \times 10^{6}\right)$ using an RNAeasy mini kit (Qiagen) according to the manufacturer's instructions. Isolated RNA was subjected to DNAse digestion according to the manufacturer's instructions (Invitrogen). Reverse transcription and cDNA amplification was carried out using the Superscript One Step RT-PCR system (Invitrogen) according to the manufacturer's instructions, using $1 \mu \mathrm{g}$ RNA starting material and primers specific for human XIAP and $\beta$ actin. A subsaturating number of amplifications enabled a semiquantitative comparison. DNA was separated by $1.1 \%$ agarose gel electrophoresis and visualised with ethidium bromide.

\section{Confocal microscopy}

Cells were fixed $48 \mathrm{~h}$ post-transfection or following stimulation with UV light, in ice-cold methanol for $5 \mathrm{~min}$. For MitoTracker staining, cells were incubated for $30 \mathrm{~min}$ prior to fixation with $150 \mathrm{nM}$ MitoTracker Red CMXRos (Molecular Probes) in medium. Following fixation, cells were washed in TBS/Tween 20 and incubated in the same buffer with $1 \%$ BSA for $30 \mathrm{~min}$ at room temperature. Cells were incubated with primary antibody diluted in the same buffer for $1 \mathrm{~h}$ at room temperature. Cyt $c$ was detected using anti-Cyt $c$ mAb 6H2.B4 (BD PharMingen), at 1:100 dilution. Cells were washed three times in TBS/Tween 20, followed by incubation with the appropriate secondary antibody for $30 \mathrm{~min}$ at room temperature. Cells were washed a further three times in TBS/Tween 20 and, where indicated, incubated with $2 \mu \mathrm{M}$ TO-PRO-3 (Molecular Probes) in TBS/Tween 20 for $5 \mathrm{~min}$. Samples were washed in distilled water and mounted on slides using Vectashield (Vector Laboratories, Burlingame, CA, USA). Images were obtained using a Leica TCS NT confocal laserscanning microscope (Leica Microsystems, Heidelberg, Germany). To minimise spectral leak-through images were obtained by sequential scanning.

\section{Acknowledgements}

We thank Drs. H Steller, R Takahashi, S Lens, H Brady, R Agami and N Divecha for generously providing plasmids and $L$ Oomen and $L$ Brocks for assistance with confocal microscopy. This work was supported by a Marie Curie Fellowship from the European Commission to $\mathrm{S}$ Tait and by the Dutch Cancer Society. 


\section{References}

1. Meier P, Finch A and Evan G (2000) Apoptosis in development. Nature 407: 796-801

2. Vernooy SY, Copeland J, Ghaboosi N, Griffin EE, Yoo SJ and Hay BA (2000) Cell death regulation in Drosophila: conservation of mechanism and unique insights. J. Cell Biol. 150: F69-F76

3. White K, Tahaoglu E and Steller H (1996) Cell killing by the Drosophila gene reaper. Science 271: 805-807

4. McCarthy JV and Dixit VM (1998) Apoptosis induced by Drosophila Reaper and Grim in a human system. J. Biol. Chem. 273: 24009-24015

5. White K, Grether ME, Abrams JM, Young L, Farrell K and Steller H (1994) Genetic control of programmed cell death in Drosophila. Science 264: 677-683

6. Lohmann I, McGinnis N, Bodmer M and McGinnis W (2002) The Drosophila hox gene deformed sculpts head morphology via direct regulation of the apoptosis activator reaper. Cell 110: 457-466

7. Brodsky MH, Nordstrom W, Tsang G, Kwan E, Rubin GM and Abrams JM (2000) Drosophila p53 binds a damage response element at the reaper locus. Cell 101: 103-113

8. Deveraux QL and Reed JC (1999) IAP family proteins-suppressors of apoptosis. Genes Dev. 13: 239-252

9. Yang Y, Fang S, Jensen JP, Weissman AM and Ashwell JD (2000) Ubiquitin protein ligase activity of IAPs and their degradation in proteasomes in response to apoptotic stimuli. Science 288: 874-877

10. Wang SL, Hawkins CJ, Yoo SJ, Mueller H-A and Hay BA (1999) The Drosophila caspase inhibitor DIAP1 is essential for cell survival and is negatively regulated by HID. Cell $98: 453-463$

11. Ryoo HD, Bergmann A, Gonen H, Ciechanover A and Steller H (2002) Regulation of Drosophila IAP1 degradation and apoptosis by reaper and ubcD1. Nat. Cell Biol. 4: 432-438

12. Wilson R, Goyal L, Ditzel M, Zachariou A, Baker DA, Agapite J, Steller H and Meier $P$ (2002) The DIAP1 RING finger mediates ubiquitination of Dronc and is indispensable for regulating apoptosis. Nat. Cell Biol. 4: 445-450

13. Hays R, Wickline L and Cagan R (2002) Morgue mediates apoptosis in the Drosophila melanogaster retina by promoting degradation of DIAP1. Nat. Cell Biol. 4: 425-431

14. Yoo SJ, Huh JR, Muro I, Yu H, Wang L, Wang SL, Feldman RMR, Clem RJ, Mueller H-A and Hay BA (2002) Hid, Rpr and Grim negatively regulate DIAP1 levels through distinct mechanisms. Nat. Cell Biol. 4: 416-424

15. Holley CL, Olson MR, Colon-Ramos DA and Kornbluth S (2002) Reaper eliminates IAP proteins through stimulated IAP degradation and generalized translational inhibition. Nat. Cell Biol. 4: 439-444

16. Christich A, Kauppila S, Chen P, Sogame N, Ho SI and Abrams JM (2002) The damage-responsive Drosophila sickle encodes a novel IAP binding protein similar to but distinct from reaper, grim and hid. Curr. Biol. 12: 137-140

17. Srinivasula SM, Datta P, Kobayashi M, Wu JW, Fujioka M, Hegde R, Zhang Z, Mukattash R, Fernandes-Alnemri T, Shi Y, Jaynes JB and Alnemri ES (2002) Sickle, a novel Drosophila death gene in the reaper/hid/grim region, encodes an IAP-inhibitory protein. Curr. Biol. 12: 125-130

18. Wing JP, Karres JS, Ogdahl JL, Zhou L, Schwartz LM and Nambu JR (2002) Drosophila sickle is a novel grim-reaper cell death activator. Curr. Biol. 12: 131-135

19. Tenev $T$, Zachariou A, Wilson $R$, Paul $A$ and Meier $P$ (2002) Jafrac2 is an IAP antagonist that promotes cell death by liberating Dronc from DIAP1. EMBO J. 21: $5118-5129$

20. Haining WN, Carboy-Newcomb C, Wei CL and Steller H (1999) The proapoptotic function of Drosophila Hid is conserved in mammalian cells. Proc. Natl. Acad. Sci. USA 96: 4936-4941

21. Du C, Fang M, Li Y, Li L and Wang X (2000) Smac, a mitochondrial protein that promotes cytochrome $c$-dependent caspase activation by eliminating IAP inhibition. Cell 102: 33-42

22. Verhagen AM, Ekert PG, Pakusch M, Silke J, Conolly LM, Reid GE, Moritz RL, Simpson RJ and Vaux DL (2000) Identification of DIABLO, a mammalian protein that promotes apoptosis by binding to and antagonizing IAP proteins. Cell 102: 43-53

23. Suzuki Y, Imai Y, Nakayama H, Takahashi K, Takio K and Takahashi R (2001) A serine protease, $\mathrm{HtrA} 2$ is released from the mitochondria and interacts with XIAP, inducing cell death. Mol. Cell 8: 613-621
24. Silke J, Verhagen AM, Ekert PG and Vaux DL (2000) Sequence as well as functional similarity for DIABLO/Smac and Grim, Reaper and Hid? Cell Death Differ. 7: 1275

25. Zimmermann KC, Ricci J-E, Droin NM and Green DR (2002) The role of ARK in stress-induced apoptosis in Drosophila cells. J. Cell Biol. 156: 1077-1087

26. Claveria C, Caminero E, Martinez-A C, Campuzano S and Torres M (2002) $\mathrm{GH} 3$, a novel proapoptotic domain in Drosophila Grim, promotes a mitochondrial death pathway. EMBO J. 21: 3327-3336

27. Claveria C, Martinez-A C and Torres M (2003) A Bax/Bak-independent mitochondrial death pathway triggered by Drosophila Grim GH3 domain in mammalian cells. J. Biol. Chem. 279: 1368-1375

28. Evans EK, Kuwana T, Strum SL, Newmeyer DD and Kornbluth S (1997) Reaper-induced apoptosis in a vertebrate system. EMBO J. 16: 7372-7381

29. Thress K, Henzel W, Shillinglaw W and Kornbluth S (1998) Scythe: a novel reaper-binding apoptotic regulator. EMBO J. 17: 6135-6143

30. Thress K, Evans EK and Kornbluth S (1999) Reaper-induced dissociation of a Scythe-sequestered cytochrome c-releasing activity. EMBO J. 18: 5486-5493

31. Marsden VS and Strasser A (2003) Control of apoptosis in the immune system: Bcl-2, BH3-only proteins and more. Annu. Rev. Immunol. 21: 71-105

32. Shirane M and Nakayama KI (2003) Inherent calcineurin inhibitor FKBP38 targets Bcl-2 to mitochondria and inhibits apoptosis. Nat Cell Biol. 5: 28-37

33. Olson M, Holley CL, Yoo SJ, Huh JR, Hay BA and Kornbluth S (2003) Reaper is regulated by IAP-mediated ubiquitination. J. Biol. Chem. 278: 4028-4034

34. Varkey J, Chen P, Jemmerson R and Abrams JM (1999) Altered cytochrome $c$ display precedes apoptotic cell death in Drosophila. J. Cell Biol. 144: 701-710

35. Dorstyn L, Read S, Cakouros D, Huh JR, Hay BA and Kumar S (2002) The role of cytochrome $c$ in caspase activation in Drosophila melanogaster cells. J. Cell Biol. 156: 1089-1098

36. Kanuka H, Sawamoto K, Inohara N, Matsuno K, Okano H and Miura M (1999) Control of the cell death pathway by Dapaf-1, a Drosophila Apaf-1/CED-4related caspase activator. Mol. Cell 4: 757-769

37. Rodriguez A, Oliver H, Zou H, Chen P, Wang X and Abrams JM (1999) Dark is a Drosophila homologue of Apaf-1/CED-4 and functions in an evolutionary conserved death pathway. Nat. Cell Biol. 1: 272-279

38. Vucic D, Seshagiri $S$ and Miller $L$ (1997) Characterization of Reaper- and FADD-induced apoptosis in a lepidopteran cell line. Mol. Cell. Biol. 17: 667-676

39. Brun S, Rincheval V, Gaumer S, Mignotte B and Guenal I (2002) Reaper and bax initiate two different apoptotic pathways affecting mitochondria and antagonized by bcl-2 in Drosophila. Oncogene 21: 6458-6470

40. Claveria C, Albar JP, Serrano A, Buesa JM, Barbero JL, Martinez-A C and Torres M (1998) Drosophila grim induces apoptosis in mammalian cells. EMBO J 17: 7199-7208

41. Olson MR, Holley CL, Gan EC, Colon-Ramos DA, Kaplan B and Kornbluth S (2003) A GH3-like domain in Reaper is required for mitochondrial localization and induction of IAP degradation. J Biol Chem 278: 44758-44768

42. Banerji J, Sands J, Strominger JL and Spies T (1990) A gene pair from the human major histocompatibility complex encodes large proline-rich proteins with multiple repeated motifs and a single ubiquitin-like domain. Proc. Natl. Acad. Sci. USA 87: 2374-2378

43. Manchen ST and Hubberstey AV (2001) Human Scythe contains a functional nuclear localization sequence and remains in the nucleus during staurosporineinduced apoptosis. Biochem. Biophys. Res. Commun. 287: 1075-1082

44. Colon-Ramos DA, Irusta PM, Gan EC, Olson MR, Song J, Morimoto RI, Elliott RM, Lombard M, Hollingworth R, Hardwick JM, Smith GK and Kornbluth S (2003) Inhibition of translation and induction of apoptosis by Bunyaviral nonstructural proteins bearing sequence similarity to Reaper. Mol. Biol. Cell 14: 4162-4172

45. Kinsella TM and Nolan GP (1996) Episomal vectors rapidly and stably produce high-titer recombinant retrovirus. Hum. Gene Ther. 7: 1405-1413

46. Werner AB, de Vries E, Tait SWG, Bontjer I and Borst J (2002) Bcl-2 family member Bfl-1/A1 sequesters truncated Bid to inhibit its collaboration with proapoptotic Bak or Bax. J. Biol. Chem. 277: 22781-22788

47. Agami R and Bernards R (2000) Distinct initiation and maintenance mechanisms cooperate to induce G1 cell cycle arrest in response to DNA damage. Cell 201: 55-66

48. Waterhouse NJ and Trapani JA (2003) A new quantitative assay for cytochrome $c$ release in apoptotic cells. Cell Death Differ. 10: 853-855 